\title{
Isolated case of left ventricular diverticulum; other aneurysmal structures of the left ventricle
}

\author{
Mahmoud Khreis, Nasir Saleem, Raya Saba
}

Department of Internal Medicine, Presence Saint Joseph Hospital, Chicago, Illinois, USA

\section{Correspondence to} Dr Nasir Saleem, nasirsaleemmd@gmail.com

Accepted 16 February 2016

\section{DESCRIPTION}

A 41-year-old man with a medical history of hypertension and hyperlipidaemia presented to the cardiology clinic, with substernal chest pain on exertion for 1 month. The pain, which occurred every day, was dull in character, non-radiating and relieved by rest. The patient was a former smoker with a 20 pack year history. He underwent an exercise stress test, which was positive for retrosternal burning consistent with angina and ECG evidence of ischaemia. Coronary angiography performed the next day revealed severe coronary artery disease, requiring stent placement to the proximal and mid left

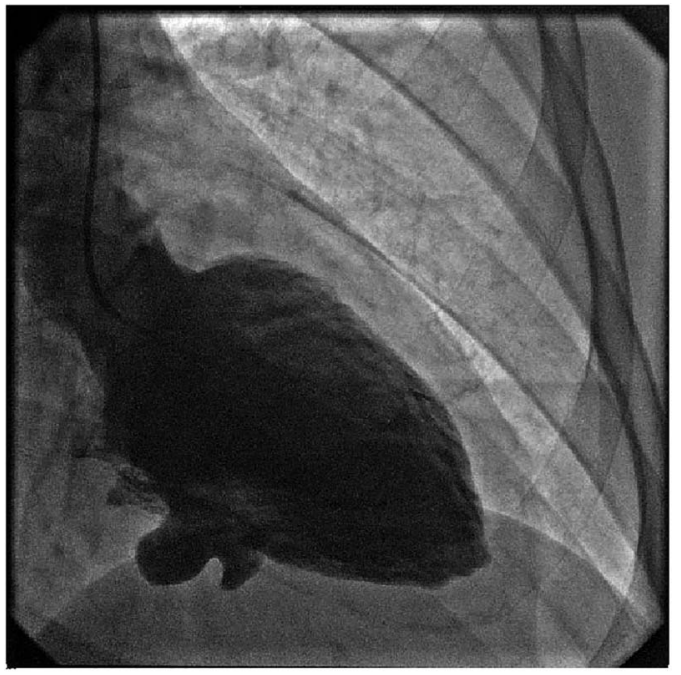

Figure 1 A ventriculogram image showing a left ventricular posterobasal diverticulum in diastole.

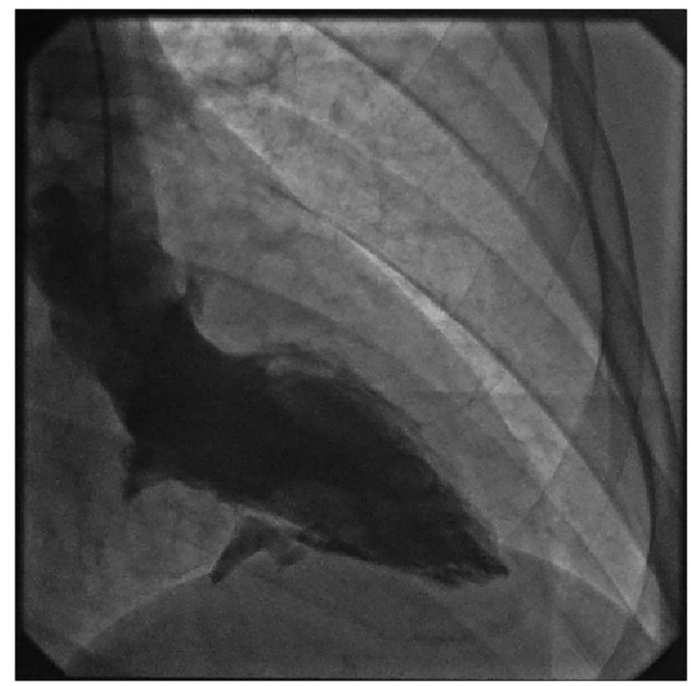

Figure 2 A ventriculogram image showing the same diverticulum in systole. anterior descending artery. Concomitantly performed ventriculography revealed a large posterobasal left ventricular (LV) outpouching (figures 1 and 2). This was characterised as a cardiac diverticulum, as it displayed normal contraction in

\section{Learning points}

- The diagnosis with the worst prognosis is left ventricular (LV) pseudoaneurysm, which is a contained rupture of the LV free wall. This may be caused by myocardial infarction, cardiac surgery, infectious endocarditis or chest trauma, and its prognosis is influenced by the nature, chronicity, underlying cause and location of the pseudoaneurysm. ${ }^{1}$ A prudent approach to postinfarction LV pseudoaneurysms is to consider performing surgery in patients with good comorbid status and in whom the precipitating event was recent, and to favour conservative management in asymptomatic patients with substantial comorbidities and a stable LV pseudoaneurysm that was found incidentally, late after the causative event. ${ }^{2}$

- LV aneurysm is a discrete region of ventricular wall that is thinner, balloons outward and exhibits either akinesis or dyskinesis. In most cases, the underlying cause is myocardial infarction, trauma, iatrogenic injury or Chagas disease. ' Survival in patients with LV aneurysm is related to age, LV function and the clinical severity of heart failure rather than to the presence of the aneurysm itself, according to data from the Coronary Artery Surgery Study (CASS) registry. ${ }^{3}$

- LV diverticulum is defined as an outpouching walled by endocardium, myocardium and pericardium, and displays normal contraction in synchrony with the rest of the ventricle. These are considered to be congenital if there is no history of conditions that have injured the myocardium. The natural history of LV diverticulum has not been systematically studied and major concerns are thrombosis, embolism, rupture, congestive heart failure, ventricular arrhythmias and valvular abnormalities. ${ }^{1}$ The true incidence of these complications is not known because of the rarity of LV diverticulum, and management decisions should be based on the clinical attributes of the individual patient with consideration given to such potential complications. 
synchrony with the rest of the ventricle. When such LV outpouchings are detected, the main differential diagnoses are pseudoaneurysm, aneurysm and diverticulum. The prognosiswhich can vary from benign to catastrophic-natural history and outcomes of LV outpouchings, differ substantially, and accurate diagnosis is crucial in guiding management decisions. Our patient was prescribed appropriate pharmacological therapy for coronary artery disease, hypertension and hyperlipidaemia, along with routine follow-up. However, no further management was planned for the cardiac diverticulum as the risk for potential complications was deemed low.

Competing interests None declared.
Patient consent Obtained.

Provenance and peer review Not commissioned; externally peer reviewed.

\section{REFERENCES}

1 Makkuni P, Kotler MN, Figueredo VM. Diverticular and aneurysmal structures of the left ventricle in adults: report of a case within the context of a literature review. Tex Heart Inst J 2010;37:699-705.

2 Eren E, Bozbuga N, Toker ME, et al. Surgical treatment of post-infarction left ventricular pseudoaneurysm: a two-decade experience. Tex Heart Inst J 2007:34:47-51.

3 Faxon DP, Ryan TJ, Davis KB, et al. Prognostic significance of angiographically documented left ventricular aneurysm from the Coronary Artery Surgery Study (CASS). Am J Cardiol 1982;50:157-64.

Copyright 2016 BMJ Publishing Group. All rights reserved. For permission to reuse any of this content visit

http://group.bmj.com/group/rights-licensing/permissions.

BMJ Case Report Fellows may re-use this article for personal use and teaching without any further permission.

Become a Fellow of BMJ Case Reports today and you can:

- Submit as many cases as you like

- Enjoy fast sympathetic peer review and rapid publication of accepted articles

- Access all the published articles

- Re-use any of the published material for personal use and teaching without further permission

For information on Institutional Fellowships contact consortiasales@bmjgroup.com

Visit casereports.bmj.com for more articles like this and to become a Fellow 